\title{
Style and addressees in the selection of dialectal vs. standard phonetic forms: Sicilian rhotics
}

\section{Chiara Meluzzi}

Dipartimento di Studi Umanistici, Università degli Studi di Pavia

chmeluzzi@gmail.com

\section{Chiara Celata}

Dipartimento di Studi Umanistici (DISTUM), Università degli Studi di Urbino 'Carlo Bo’ chiara.celata@uniurb.it

\begin{abstract}
This study is about the production of singleton and geminate rhotics by young adult Sicilian speakers, whose native languages are Italian and a Sicilian dialect, during speech interactions with different interlocutors. As in many other languages, /r/ works as a sociolinguistic variable in the Sicilian area, conveying social and geographical information about the speaker. We will show that it also conveys information about the communicative and interactional dynamics with peers speaking either Italian or Sicilian dialects. We propose that in the process of selecting the relevant variants of the $/ r$ / variable, the speakers are guided by the socio-communicative context and the phenomena of mutual convergence between interlocutors. ${ }^{1}$
\end{abstract}

Keywords: standard/dialect dynamics; rhotics; Italian; Sicilian; speech style; speech accommodation.

Riassunto. Stile e interlocutore nella selezione di forme fonetiche dialettali vs. standard: le rotiche del siciliano

Questo studio si occupa della produzione delle rotiche in contesto scempio e geminato da parte di parlanti siciliani, le cui lingue native sono l'italiano e un dialetto siciliano, durante conversazioni con diversi interlocutori. Come in molte altre lingue, la /r/ ricopre il ruolo di variabile sociolinguistica nell'area siciliana, veicolando informazioni sociali e geografiche sul parlante. Lo studio mostra come la /r/ veicoli anche informazioni sulle dinamiche comunicative e interazionali nei dialoghi in italiano e in dialetto siciliano. Nel processo di selezione delle varianti della /r/, i parlanti appaiano influenzati dal contesto socio-comunicativo e da fenomeni di convergenza reciproca tra interlocutori.

Parole chiave: dinamiche standard/dialetto; rotiche; italiano; siciliano; stile di elocuzione; accomodazione.

1. This study has been jointly conceived and written by the two authors. However, for academic purposes, Chiara Meluzzi is responsible for sections 2 and 3 of the paper and for taking care of the annotation of the phonetic data; Chiara Celata is responsible for sections 1 and 4 of the paper and for devising and recording the corpus. 


\section{Introduction}

The standard/dialect dynamics in the Italo-Romance area has been traditionally described as Italian speakers having a native competence of at least two distinct language varieties. The first is the local Italo-Romance dialect, a "primary dialect" according to Coseriu's (1980) terminology, signifying direct evolution from Latin. The second is the regional variety of Italian, also called regionally accented Italian, basically the result of the different shapes that modern Italian has assumed during its spread across the peninsula. The two language varieties differ not only from a historical point of view, but also for the scale of their geographic differentiation, which is more granular for dialects whereas regional Italian varieties cover larger territories, sometimes encompassing the boundaries of administratively defined "regions". Moreover, the sociolinguistic contexts of use are also different. The dialect is confined to informal conversations and can be identified as a 'low' variety according to Ferguson's (1959) model of diglossia; Italian (in its neo-standard form, e.g. Berruto, 1987) represents the variety of the official uses but is also widely used in informal conversations, thus leading to a complex sociolinguistic condition characterized by asymmetric relations (Bellman, 1998) and frequent codeswitching phenomena (Berruto, 1987).

There is strong inter- and intra-regional variation in the way the standard/ dialect dynamics manifests itself. For instance, in the North West areas, the use of the dialect is strongly reduced, mostly due to a more massive increase of the standard variety in everyday life (Auer, 2005), while in the North East, South and Sicily dialects still enjoy great vitality (truly diglottic repertoires, according to Auer, 2005). A very complex situation has been documented for Sicily by the most recent sociolinguistic surveys. Note that Sicilian dialects are among those dialects that structurally diverge the most from Florentinebased Italian, and Sicilian-accented Italian retains some aspects of the dialect at different grammatical levels. Data of self-reported language use quoted in D'Agostino \& Paternostro (2013) emphasize a systematic increase of the number of speakers who use both Italian and Sicilian in both formal and informal situations: in 1988, the dialect was the only language used in the family by $48 \%$ of the speakers, whereas in $2006,46 \%$ of the interviewees reported to use both Italian and the dialect with parents and $49 \%$ reported to use both Italian and the dialect with friends.

An additional character of the standard/dialect dynamics in Sicilian territories, that is worth recalling here, is that the dialect loses ground as language of primary socialization, but at the same time, most of the youngest speakers start to use the dialect as an L2, particularly within the peer group (Alfonzetti, 2014, 2017; Scaglione, 2016). Many authors suggest that the relationship between young speakers and the dialect is ambiguous. On one hand, we assist to an emotional attachment to something that is perceived as part of one's own traditions and to its widest exploitation as a code of expressive communication (also in a mixture with other dialects or languages, such as English). 
On the other hand, the use of the dialect is subject to censorship because it is not entirely free from connotations of provinciality and social subordination.

These complex sociolinguistic dynamics related to the co-presence of Italian and dialect among (young) Sicilian speakers can be understood also in the framework of more general standard/vernacular dynamics, as they are attested at the European level. Two apparently opposite tendencies have been shown to regulate the interplay between standards and vernaculars (Auer, 2005; Kristiansen \& Coupland, 2011): an increasing regionalisation of the local vernacular varieties is counterbalanced by the creation of new standards as the result of original standard languages acquiring regional or social features. As a general result of this process, the geographic differentiation among varieties tends to decrease. As other authors have argued, if the sociolinguistic variables are no longer used to primarily index the geographic origin, their use could be interpreted as part of the construction of an individual's social identity (cf. Mendoza-Denton, 2008; Nycz, 2015; Morris, 2017).

How to specifically classify, and quantify, the coexistence of vernacular and regional or supra-regional forms of speech is, however, still matter of debate (e.g. Dal Negro \& Vietti, 2011; Crocco, 2017). Pronunciation is probably the domain in which the speaker is maximally free to make very small changes in her/his own production to convey specific extra-linguistic meanings, thus potentially generating a very high number of pronunciation variants for one given variable. The dynamics of code-switching may well account for morpho-lexical, syntactic and discourse-level phenomena of alternation. As widely demonstrated for the Italo-Romance (e.g. Berruto, 1987; Cerruti \& Regis, 2005) and Sicilian domains (e.g. Alfonzetti, 1992), in code-switching each language switch has a specific pragmatic or socio-communicative function (Auer, 1995). For the phonetic and phonological levels, it can equally be hypothesized that variation related to the standard/dialect dynamics conveys socio-communicative meanings, but the question is complicated by the fact that speech variation, particularly when associated to socio-indexical functions (Foulkes, Scobbie, \& Watt, 2010), provides statistical differences in the distribution of a plurality of forms rather than categorical oppositions between a dialectal and an Italian form. This opens methodological questions on how to elicit the forms of the alternation in the individual speech repertoire as well as how to study the alternated use of pronunciation variants in speech interactions with multiple pragmatic and indexical functions. In sociophonetic research on Italo-Romance varieties, the classical approach consists in analysing variation within either the dialect or the regional variety of Italian and to compare, directly or mediated by previous knowledge, the most prototypical realizations of each of the two languages (e.g. Marotta, 2014; Crocco, 2017; Nodari, Celata, \& Nagy, 2019; Meluzzi, 2020). However, disregarding extra-linguistic factors that may lead to various (including non-prototypical) dialectal and regional Italian pronunciation patterns risks to produce an undersampling of speech variation and to hinder observation of potential hybridization phenomena. 
Based on these premises, we developed a methodology to approach the standard/dialect dynamics from the point of view of within-subject fine phonetic variation across multiple speaking conditions. Accordingly, this study examined within-subject phonetic variation in the speech of young adult Sicilian speakers, whose native languages are Italian and a Sicilian dialect, during a variety of speech tasks. The variable under scrutiny was the realization of intervocalic singleton and geminate $/ \mathrm{r}(:) /$. Rhotics are among the most salient pronunciation features of the Sicilian dialects, not only with respect to Italian but also to other southern Italian dialects (Rohlfs, 1966; Piccillo, 1969; Ruffino, 2001). Rhotic sounds are known for showing high degrees of both syntagmatic and paradigmatic variation both cross-subject within a speech community and in the speech of individual subjects (e.g. Van de Velde \& van Hout, 2001). Moreover, $/ \mathrm{r} /$ is a sociophonological variable in many speech communities since much of its variation is used by the speakers to index sociological differences and communicative functions (see Scobbie, 2006, for a review). In this study, we examined rhotics production by a target speaker and his interlocutors when speaking in Italian as well as in the dialect, in sentence reading tasks as well as in dialogues, and in interactions with interlocutors having strong as well as weak familiarity relations with the target speaker.

The notion of speech style is central to our understanding of the selection of rhotic variants. It is evident that a stylistic variation between sentencereading task and dialogues can primarily be interpreted in a Labovian way as a difference in the attention paid to speech (Labov, 1972). However, to this speaker-oriented notion of attention to speech other models have critically opposed the fact that in the selection of speech styles a more central role is played by the social-indexical aspects of the interaction between interlocutors in a dialogue (e.g. Bell, 1984; Coupland, 2001; Schilling-Estes, 2002; see also Babel, 2010, for the notion of phonetic accommodation). These proposals, based on social constructivist models, focus on identity building in speech interaction and show that speech style is predicted by effects of speaker- or audience-design. More recently, and with particular reference to a bilingual Indian English and American English speaker, Sharma (2018) emphasizes the interplay of language dominance, cognitive factors (such as attentional effects) and social-indexical factors in explaining the selection of speech variants, suggesting that the primary vernacular (or the native dialect) may have a privileged status in the speaker's repertoire and surface when attention drops down, irrespective of social dynamics. Sharma's (2018) work is also of fundamental importance for our study because it states that within-speaker variation is the main locus of investigation to understand the interplay of multiple factors that predict phonetic variation, particularly in the case of multilingual speakers.

Based on these premises, this study investigates within-subject speech variation in the realization of rhotics as predicted by language-internal and language-external (i.e. socio-communicative) factors. We had specific expectations about which rhotic variants should surface in each language, that are detailed below. We assigned each variant its relative weight in the different subsets of 
the speech corpus, based on its percentage of occurrence. More generally, we compared variation patterns predicted by the language (Italian vs. the dialect) with those predicted by style as attention to speech (word list vs. dialogue) and those predicted by style as accommodation to the addresse (dialogues with different interlocutors, with whom the speaker entertains different degrees of familiarity; e.g. Cukor-Avila \& Bailey, 2011; Podesva, Jamsu Reynolds, Callier, \& Baptiste, 2015). In agreement with current sociolinguistic literature on the standard/dialect dynamics in the Italo-Romance domain, our underlying hypothesis was that phonological variables were used by young Sicilian speakers not only to index geographic origin but also for socio-communicative purposes. According to such hypothesis, phonetic variants are no longer predictable by language only (Italian vs. the dialect), but by a combination of language- and speaker-related factors, including changing speaking styles and changing interlocutors in dialogue interactions.

\section{Methodology}

\subsection{Corpus and procedure}

The data for this study comes from the SoPhISM corpus (SocioPhonetics of speech Interaction: Sicilian, Multimodal corpus, cf. Celata, Meluzzi, \& Ricci, 2016). SoPhISM is an acoustic and articulatory sociophonetic corpus documenting several speech varieties and styles produced by fluently 'bilingual' Sicilian-Italian speakers under the age of 30 from central and southern areas.

The corpus design included a multidimensional continuum of speakerspecific varieties in diversified interactional contexts (Figure 1). These diverse contexts were the result of the intersection of three different parameters: language variety (Italian vs. Sicilian dialect), style or attention paid to speech (dialogue vs. sentence reading) and, for the dialogues, the level of familiarity of the speaker with his/her interlocutor (high vs. low vs. very low).

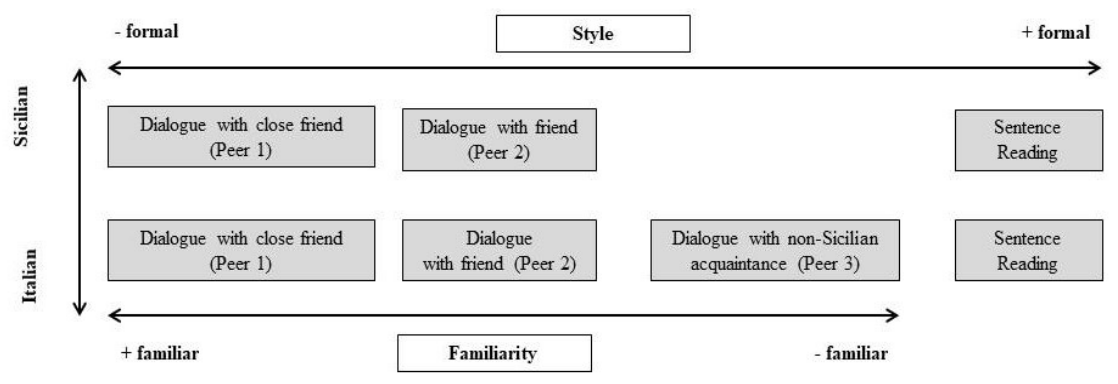

Fig. 1. Language variety, style and familiarity co-variation in the SoPhISM corpus. 
In this paper, we focus on the production of one speaker, a young male speaker from Modica (in the South East of the island), who performed sentence reading tasks and map-task dialogues with two different interlocutors. The speaker was 21 years old at the time of the recordings, hold a first-level university degree and self-reported full active and passive competence in his dialect. Although his primary socialization in the family environment occurred in the dialect, which gives the dialect a 'primacy' in time as well as affective terms, Italian soon became as important as the dialect in his everyday social and educational life. Based on his own self-evaluation, the speaker could therefore be considered an Italian-Sicilian balanced bilingual speaker. The two interlocutors were a male close-friend from Modica and a male friend from the nearby town of Leonforte (Central-Eastern area, phonetically very close to the South East, cf. Piccitto, 1959, p. 174; Ruffino, 2001, p. 45). The dialogues and the sentence reading tasks were performed once in Italian and (on a different occasion, several days later) in Sicilian. In the sentence list and the dialogues, the target words contained singleton and geminate rhotics in intervocalic context. For each language, approximately the same target words appeared in the list and in the map-tasks, although in the latter case the rate of repetition of individual words could slightly vary due to specific interactional dynamics. The sentence lists were repeated twice (in the case of Italian) or three times (in the case of Sicilian).

The rhotic variants were identified through visual inspection of waveforms and spectrograms. They were annotated and analysed according to the protocol developed in Celata, Vietti, \& Spreafico (2019); details on how the annotation system was implemented in the SoPHISM corpus as well as on the phonetic variants that were found in the corpus are in Celata et al. (2016). Basically, for each rhotic sound 'constrictions' and 'apertures' are identified. Rhotics can be realised with a single consonantal gesture (a constriction) or a combination of constriction and aperture gestures. In the latter case, rhotics can correspond to trills, which are prototypically made of a repetition of short constrictions and apertures, or to taps, whenever a svarabhakti vowel accompanies the constriction gesture. Fricative and approximant rhotics tend to show a single constriction; fricatives are characterized by an intense aperiodic noise located at mid-high spectral frequencies, whereas approximants show a clearly detectable formant structure along the duration of the entire consonant.

Table 1 summarizes the number of $/ \mathrm{r} /$ singleton and geminate tokens as produced by the target speaker across speech tasks and language varieties, which were analysed in the current study. Moreover, intervocalic singleton and geminate $/ \mathrm{r} /$ tokens from the production of the two interlocutors (Peer 1 and Peer 2) were segmented and annotated. This accounted for an additional 84 rhotic tokens (Table 2 ). 


\begin{tabular}{|l|l|l|l|l|l|l|l|}
\hline & Italian & & & $\begin{array}{l}\text { Sicilian } \\
\text { dialect }\end{array}$ & & & Total \\
\hline & singletons & geminates & Total & singletons & geminates & Total & \\
\hline $\begin{array}{l}\text { Sentence rea- } \\
\text { ding }\end{array}$ & 70 & 48 & 118 & 220 & 125 & 345 & 463 \\
\hline $\begin{array}{l}\text { Map task } \\
\text { (with Peer 1) }\end{array}$ & 22 & 23 & 45 & 26 & 20 & 46 & 91 \\
\hline $\begin{array}{l}\text { Map task } \\
\text { (with Peer 2) }\end{array}$ & 19 & 18 & 37 & 35 & 14 & 49 & 86 \\
\hline Total & 111 & 89 & 200 & 281 & 159 & 440 & 640 \\
\hline
\end{tabular}

Table 1 . Occurrences of singleton and geminate $/ \mathrm{r} /$ tokens in the production of the target speaker, split by language variety and speech task.

\begin{tabular}{|l|l|l|l|l|l|l|l|}
\hline & Italian & & & $\begin{array}{l}\text { Sicilian } \\
\text { dialect }\end{array}$ & & Total \\
\hline & singletons & geminates & Total & singletons & geminates & Total & \\
\hline Peer 1 & 10 & 7 & 17 & 12 & 13 & 25 & 42 \\
\hline Peer 2 & 13 & 13 & 26 & 3 & 3 & 6 & 32 \\
\hline Total & 23 & 20 & 43 & 15 & 16 & 31 & 74 \\
\hline
\end{tabular}

Table 2. Occurrences of singleton and geminate $/ \mathrm{r} /$ tokens in the production of Peer 1 and Peer 2, split by language variety.

Speech data were collected in a soundproof room at the phonetics laboratory of Scuola Normale Superiore (Pisa). Recordings were performed with the acoustic output recorded with a Shure microphone placed in front of the speaker at a distance of about $30 \mathrm{~cm}(44 \mathrm{kHz}, 16$ bit). In map task dialogues, the interlocutors' speech was also recorded by mean of a Shure microphone connected to a portable Edirol R-09HR (44 kHz, 16 bit).

\subsection{Hypotheses}

Based on the dialectological literature (e.g. Varvaro, 1988; Ruffino, 2001), we expected that the singletons and geminate rhotics were realized as follows. For intervocalic singletons, Sicilian-accented Italian and the Sicilian dialect should not differ, to the extent that in both varieties an apical tap [r] is the most common realization. For geminates, we expect apical trills [r:] in Italian and postalveolar fricatives [z:] in the dialect. However, as explained above, our hypothesis is that the language variable only predicts part of phonetic variation, because factors related to the socio-communicative situation, such as speech style and interlocutor's identity, play an important role too. Moreover, it should be considered that the singleton and geminate contexts differ with respect to the social significance of the variants (Labov, 2001) as well as for the degree of conscious awareness on the part of speaker-listeners (Foulkes et al., 2010). Variation associated to the geminate variants is above the level of the speakers' conscious awareness, with the dialectal form playing the role of 
a sociolinguistic marker or stereotype that the speakers (not only from Sicily) may comment on overtly, to the extent that it signals the speaker's regional origin. Concerning the intervocalic singleton, some authors report that the dialect shows a postalveolar pronunciation of all singleton alveolars, including the rhotics (e.g. Ruffino, 2001, p. 54). Moreover, intervocalic /d/ may be realized as a rhotic sound in the Sicilian dialects (e.g. Italian piedi 'feet' > Sicilian ['peri]). Therefore, $/ \mathrm{r} /$ variation associated to the intervocalic singleton still has socio-indexical value in Sicilian, but we believe that this is lower than in the case of the geminate, also in consideration of a generally reduced phonetic salience of singletons as opposed to geminates.

\section{Results}

\subsection{Italian vs. Sicilian dialect}

As discussed with details in Celata et al. (2016), the most frequent phonetic variants that were found in the corpus where apical trills [r:], apical taps [r], postalveolar fricatives [z:], two-constriction tap-fricative variants or spirantized rhotics [ [ $\left.i_{1}^{0}\right]$, and alveolar approximants [ $\iota$ ]. In what follows, we analyse the percentage of occurrence of these variants in each relevant subset of the corpus, as defined by the three factors of language, style and (for dialogues) familiarity with the interlocutor. Spirantized rhotics where collapsed with postalveolar fricatives into a single category of fricative realizations; as a matter of fact, in spite of being articulatorily different and representing two potentially different stages of the sound change involving canonical constriction-aperture rhotics (Celata et al., 2016), these two variants are likely to be perceptually almost undistinguishable.

We first analysed the production of the target speaker across languages (Italian and Sicilian dialect), pooling together the data for singletons and geminates. Figure 2 shows that the four variants were not equally distributed in Italian and the dialect. In the former taps and trills prevailed, occupying the largest part of the phonetic space (93\% of the total occurrences). By contrast, in the dialect, trills were not that frequent (18\% of the occurrences, as opposed to $40 \%$ in Italian) and the use of fricatives increased (from 5\% in Italian to $26 \%$ in the dialect). Approximants were also more frequent in Sicilian (4\%) than in Italian (2\%). The only variant that did not change across languages was the tap $52 \%$ of the occurrences both in Italian and in the dialect). Another difference between the two languages was that in Italian there seemed to be almost the same proportion of variants across speech tasks (list reading, dialogue with Peer 1 and dialogue with Peer 2) whereas in the case of the dialect, the three speech tasks differed from one another. This was evident not only when we compared the list reading with the dialogues, but also when we compared the two dialogues with each other. For instance, trills were used more often in the dialogue with Peer $1(30 \%)$ than with Peer $2(14 \%)$, whereas 
for approximants the trend was the opposite ( $4 \%$ vs. $12 \%$, respectively); when taken together, the two dialogues exhibited a more frequent use of approximants $(8 \%)$ than the sentence reading task $(3 \%)$.

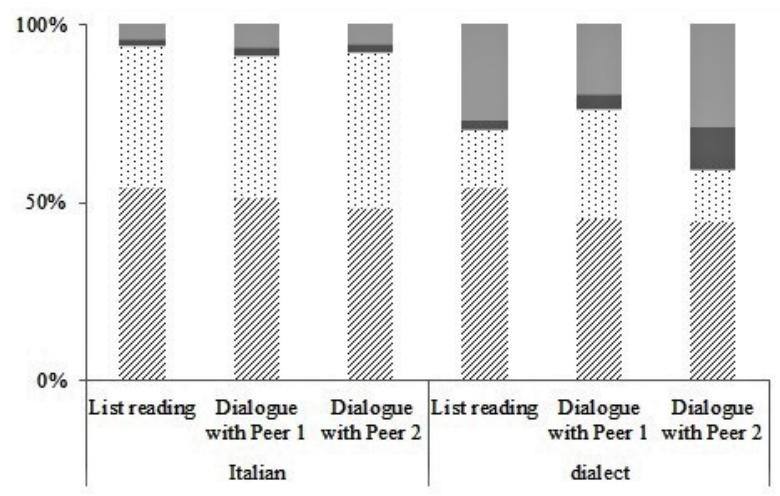

Fig. 2. Proportion of $\mathrm{R}$ variants produced by the target speaker in each speech task as a function of language and (for dialogues) interlocutor. Intervocalic singletons and geminates conflated. Striped bars correspond to taps, dotted to trills, dark grey to approximants, light grey to fricatives.

In sum, there were language-related differences in the distribution of rhotic variants, to the extent that not only the speaker changed his overall pronunciation pattern depending on the language, but the dialect also exhibited more variation than Italian depending on factors related to the communicative context.

In the next sections, language-unrelated differences are further explored, separately for singletons and geminates. In addition to the target speaker, the speech of the two interlocutors is analysed. Data for Italian are presented first (\$3.2), then rhotic realization in the dialect is discussed (\$3.3).

\subsection{Italian}

Figure 3 shows the proportion of rhotic variants of singleton $/ \mathrm{r} /$ when the target speaker and each of his interlocutor spoke Italian.

In the sentence-reading task, the large majority of the singletons was realized as a tap (91\%), and a few items were produced with an approximant or even a trill. The same occurred in the dialogues. Peer 1 and Peer 2 were also consistent with the pattern shown by the target speaker, although Peer 2 showed less taps $(77 \%)$ and a larger proportion of approximants.

Concerning the geminates (Figure 4), the target speaker showed a large majority of trills $(90 \%)$, and a few fricatives in the sentence reading task. The same picture ( $89 \%$ of trills and $11 \%$ of fricatives) could be found in the dialogue with Peer 2; Peer 2, on his turn, produced trills in 53\% of the cases only, and the remaining $47 \%$ corresponded to approximants. The target speaker 
and Peer 2 showed therefore two different patterns in the production of Italian geminates. In the case of the dialogue with Peer 1, the situation was different. Peer 1 produced trills in $31 \%$ of the cases; geminates were mostly realized as taps $(56 \%)$, and in $13 \%$ of the cases, as approximants. In the interaction with Peer 1, the target speaker changed his pronunciation pattern with respect to both the list reading task and the dialogue with Peer 2: as a matter of fact, his percentage of trills dropped to $75 \%$; taps, which were absent in the sentence reading and in the dialogue with Peer 2, were present in the dialogue with Peer 1 , covering $12 \%$ of the realizations of geminate rhotics.

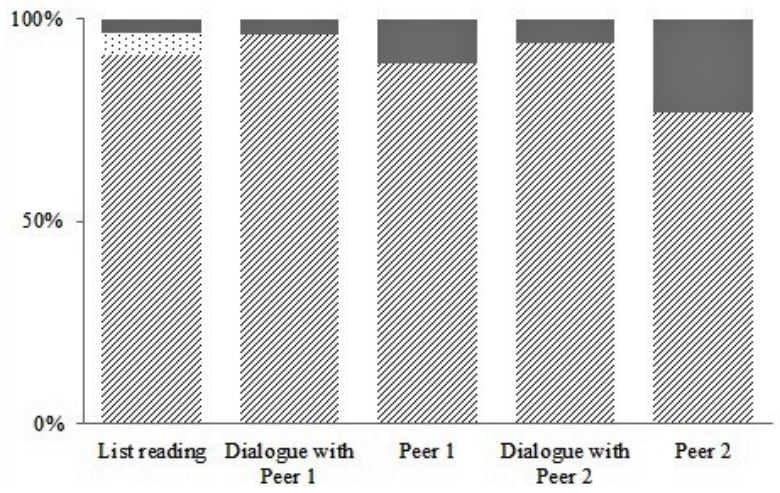

Figure 3. Proportion of $\mathrm{R}$ variants produced for singleton $/ \mathrm{r} /$ by the target speaker and his interlocutors when speaking Italian. Striped bars correspond to taps, dotted to trills, dark grey to approximants, light grey to fricatives.

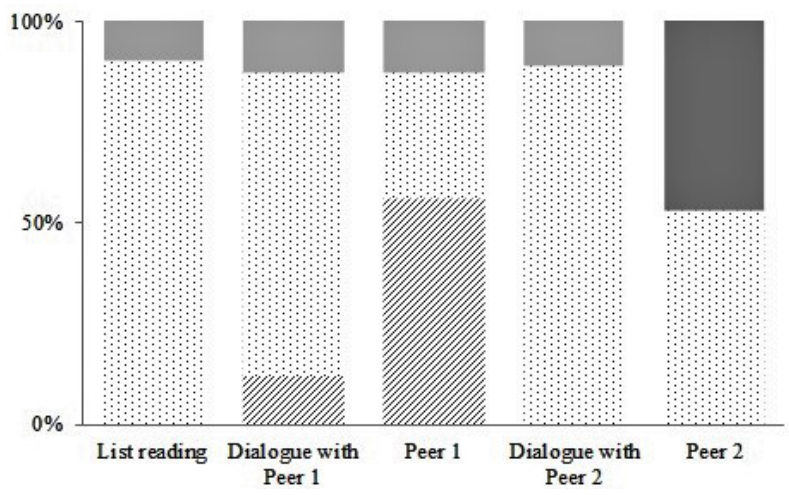

Figure 4. Proportion of $\mathrm{R}$ variants produced for geminate /r/ by the target speaker and his interlocutors when speaking Italian. Striped bars correspond to taps, dotted to trills, dark grey to approximants, light grey to fricatives. 


\subsection{Sicilian dialect}

In the dialect, intervocalic singletons (Figure 5) were produced by the target speaker as taps in $74 \%$ of the items of the list reading task, the rest being fricatives (14\%) or trills ( $9 \%$; an additional $3 \%$ were approximants). In dialogues, Peer 1 showed a very similar pattern, and the target speaker also showed no significant difference with respect to the reading task while interacting with Peer 1. In contrast, Peer 2 realized singletons as approximants, and only very few occurrences of taps could be found in his production. In the interactions with Peer 2 , the rate of tap production by the target speaker decreased $(62 \%)$ and the rate of approximants and fricatives increased (19\% and 13\%, respectively).

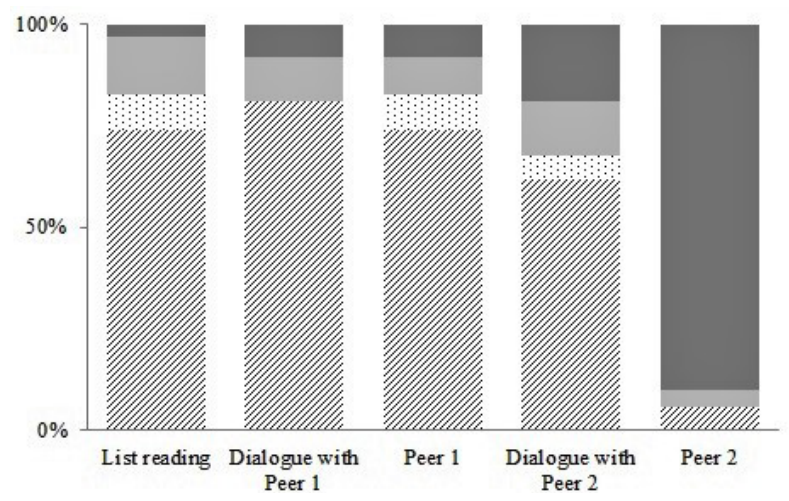

Figure 5. Proportion of $\mathrm{R}$ variants produced for singleton $/ \mathrm{r} /$ by the target speaker and his interlocutors when speaking dialect. Striped bars correspond to taps, dotted to trills, dark grey to approximants, light grey to fricatives.

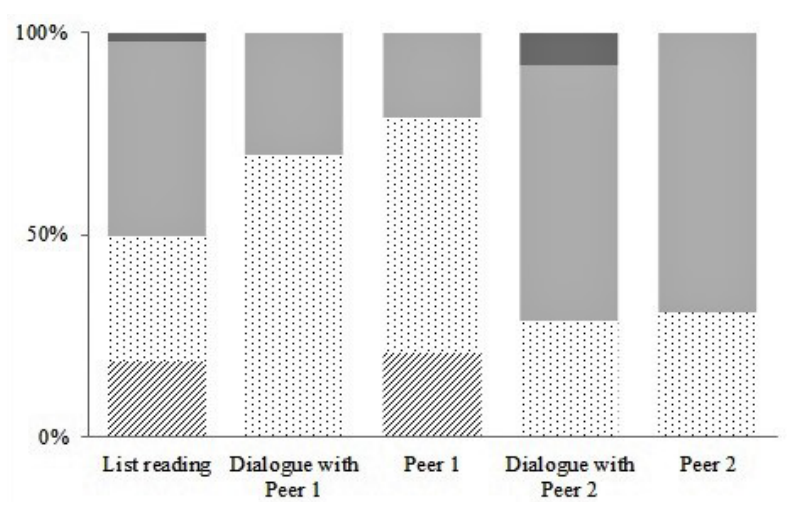

Figure 6. Proportion of $\mathrm{R}$ variants produced for geminate / $\mathrm{r} /$ by the target speaker and his interlocutors when speaking dialect. Striped bars correspond to taps, dotted to trills, dark grey to approximants, light grey to fricatives. 
Concerning geminates (Figure 6), the target speaker produced trills in only $31 \%$ of the cases in the reading task, with a larger proportion of fricatives $(48 \%)$ and an additional $19 \%$ of taps. By contrast, in the dialogue with Peer 1 , trills increased up to $70 \%$ ad fricatives decreased to $30 \%$. Peer 1 also appeared to produce much more trills $(58 \%)$ than fricatives $(21 \%)$ and taps $(21 \%)$. However, when interacting with Peer 2, the target speaker produced fricatives in up to $63 \%$ of the cases and trills in only $29 \%$; this proportion was very similar to that shown by Peer 2, who produced fricatives in $69 \%$ and trills in $31 \%$ of the cases.

\section{Discussion}

In this study we have analysed rhotic production by a young bilingual ItalianSicilian speaker and two of his interlocutors during sentence reading tasks and map-task dialogues. We have proposed a methodological approach for the investigation of speech variation which capitalizes on the view that, as recently proposed (Berruto, 1987; Cerruti \& Regis, 1995; Bellman, 1998; Auer, 2005; Kristiansen \& Coupland, 2011; Alfonzetti, 2014), the linguistic repertoire of young dialectal speakers is a continuum of varieties whose different configuration is mostly predicted by the communicative situation and the pragmatic, stylistic and socio-indexical use of features originally devoted to geographic differentiation. Therefore, in the approach proposed here, varieties of Italian and of Sicilian dialect were elicited to reproduce an image, albeit fragmentary and incomplete, of the complexity of the linguistic repertoire of young Sicilian dialectal speakers, where the boundaries between the vernacular and the supra-regional language may themselves be elusive.

As an example of such elusiveness, we can consider the way in which the target speaker implemented the phonological contrast between singleton and geminate in dialogue speech. Recall that, as explained in $\$ 2.2$, the structural distance between Italian and the Sicilian dialect was expected to be large for the geminates ([r:] and [z:], respectively) and very small or non-existing for the singleton (tap in both cases). In Italian, the contrast between singleton and geminate was phonetically achieved by opposing the tap (with a small proportion of fricatives) to the trill (with a small proportion of approximants), while in the dialect there was the opposition between the tap alternating with fricatives, approximants and trills (for the singleton), and an about equal proportion of fricatives and trills (for the geminate). Thus the implementation of the contrast by our target speaker in dialogue speech showed that the structural distance between the two languages actually was a difference in the statistical distribution of the variants. What the speaker actually does, when faced with a phonetic repertoire which has expanded thanks to the possibility of making the two linguistic systems coexist, is to variably realize phonological distinctions by virtue of the increased number of available phonetic options.

More specifically, we have hypothesized that speech variation was not only present, but could also be predicted in part by the language (Italian vs dialect) 
and in part by factors related to the communicative situation, including style (or attention to speech, Labov, 1966), and proximity between the speaker and his addressee (Giles, Coupland, \& Coupland, 1991).

Concerning the first point, that is, language-related variation, we did find, as expected, that geminate rhotics were differently realized in the dialect and in Italian: there were more fricative realizations in dialectal geminates than in Italian geminates. However, the pattern was not categorical, and fricatives were the majority variant, consistently with the expectations, only in Peer 2 speech and when the target speaker interacted with Peer 2. In the case of the singleton, our expectations about the substantial similarity of rhotic production in the dialect and in Italian was mostly confirmed, given that the tap was overall the prevalent variant in both languages. However, there was at least one condition in which the tap was not the most frequently used variant for the singleton rhotics, and this occurred in the speech of Peer 2, which showed instead a prevalence of approximants. Approximants were also present in the Italian speech of Peer 2, albeit in a much smaller proportion, thus indicating that the dialectal and the Italian pronunciations of the singleton rhotics were different for this speaker.

As anticipated above, another aspect of differentiation was the way in which the two languages tolerated variability in rhotics production across speech conditions. As shown by Figure 2, the target speaker changed its way of producing rhotics in dialogues as compared to the reading task in a much more straightforward way when he was speaking the dialect, rather than when he was speaking Italian. The same can be said with respect to changes across dialogues, that is, phonetic changes related to changing addressees. This data thus seem to suggest that stylistic and communicative varieties of the dialect are more different from each other than stylistic and communicative varieties of Italian are. This could be interpreted as the use of the dialect being more flexible than the use of Italian with respect to language-external demands of change, a suggestion which also comes from other findings of the current study that are discussed below. Although more substantive evidence should be collected in order to confirm this apparent trend, it is nevertheless possible to anticipate that our findings are not consistent with the view that primary dialects are residual varieties in the contemporary Italian sociolinguistic landscape; rather, our findings point to the possibility that dialectal linguistic usages are agentive (Coupland, 2001) and actively exploited by the speakers for communicative, indexical, pragmatic or social purposes (e.g. Alfonzetti, 2014).

Concerning the second point, that is, variation related to speech style, we compared the sentence reading task with map-task dialogues, again for Italian and the Sicilian dialect. As anticipated above, with found more style-related variation in the dialect than in Italian (Figure 2). However, in both languages, style-related variation was more present in the case of the geminate (Figure 4 and 6) than in the case of the singleton (Figure 3 and 5). This is not surprising given that singletons are shorter and less salient from a phonetic point of view; moreover, they are also lower in the level of speakers' self-consciousness 
from the socio-indexical point of view. Style-related variation appears to be particularly relevant in the production of the rhotic geminate in the dialect, where the sentence reading task elicited a less systematic pattern of variation than the two dialogue tasks. In particular, the production of taps was totally unexpected according to the dialectological literature, and was also unmotivated from the point of view of speaker-specific phonetic habits, given that no tap is used by the target speaker in other speech tasks. It is possible that the sentence reading task was not entirely ecological as a speech task to be realized in the dialect. This might be at the origin of the apparently unsystematic pattern of variation exhibited by the target speaker.

As a third point, we investigated whether part of the variation could be related, within the dialogue condition, to different interlocutors and therefore to different patterns of mutual convergence between the target speaker and his addressee (Giles et al., 1991; Babel, 2010). We found extensive evidence of accommodation between interlocutors in the dialect, and less extensive in Italian. In the former case, we found that the proportion of fricative realizations in the production of the geminate rhotics changed significantly in the two dialogues, and in strict correspondence with the proportion of fricative produced by the two interlocutors (Figure 6). For singletons, there was evidence of accommodation between the target speaker and Peer 2 as far as the increase in the use of approximants was concerned. By contrast, in the case of Italian, we found evidence of accommodation in the production of geminates only; both the target speaker and Peer 1 introduced taps among the possible options, in spite of the fact that taps were absent from other speech tasks of the target speaker and from Peer 1 speech.

Though limited to a necessarily reduced speech sample, these findings further suggest that the dialect is the locus of socio-communicative variation to a larger extent than Italian. This finding is consistent with other scholars' claim on the importance of the first-learned speech variety in shaping withinspeaker stylistic variation (Sharma, 2018). In our case, this importance is not cued by the fact that the speaker defaults to it when attention is diverted and irrespective of the social dynamics (as in Sharma, 2018), but rather by the fact that a larger amount of style- and speaker-related variation is possible in that variety than in Italian. Moreover, the view that the Sicilian dialect acquires an important communicative function within the repertoire of young speakers, as promoted for instance by current sociolinguistic investigations of codeswitching (e.g. Alfonzetti, 2017) is therefore confirmed, on a different descriptive scale, by our data. This also open the question on how properly define vernacular, regional and supra-regional forms, in terms of quantity and quality of phonetic features. Further research on within-speaker variation in the sense proposed here will help defining the nature of the continuum between local and supra-regional forms.

Our data also reveal that phonetic convergence is stronger, or more frequent, between the target speaker and Peer 2 than between the target speaker and Peer 1 . This could be counter-intuitive considering that Peer 1 is a close 
friend of the target speaker and there is a higher degree of personal proximity between the two. However, it should also be recalled that Peer 2, differently from Peer 1, comes from a different town. This could explain the higher degree of differentiation in the selection of phonetic variants between the target speaker and Peer 2. Higher phonetic differences are likely to be perceptually more salient; the more distinct the speech production patterns, the more useful (or automatic, cf. Pickering \& Garrod, 2004) the accommodation to increase the levels of mutual convergence during dialogue interactions.

Future research will have to search for additional evidence in support of the findings proposed here based on the production strategies of a single individual speaker and his interlocutors. In particular, a larger speech sample, including other phonetic variables, will allow tracking the process of phonetic convergence during the evolution of the dialogues. Moreover, we will have to investigate whether the degree of mutual convergence between the interlocutors in a dialogue increases (or decreases) with time, that is, at different points of the dialogue. More varied dialogue conditions, not limited to map-task conditions, are also needed in order to precisely understand the role of sociocommunicative variation in Italian young speakers' multilingual repertoires.

\section{Acknowledgements}

This research was supported by Scuola Normale Superiore Grant N ${ }^{\circ} 750 /$ GR13 "Modeling Speech Variation in the Socio-Communicative Context" to the second author.

\section{References}

Alfonzetti, G. (1992). Il discorso bilingue: Italiano e dialetto a Catania. Milano/Pavia: Franco Angeli.

Alfonzetti, G. (2014). Age-related variation in code-switching between Italian and the Sicilian dialect. Athens Journal of Philology, 2(1), 21-34.

Alfonzetti, G. (2017). Italian-dialect code-switching in Sicilian youngsters. Sociolinguistic Studies, 11(2-4), 435-459.

Auer, P. (2005). Europe's sociolinguistic unity, or: A typology of European dialect/ standard constellations. In N. Delbecque, J. van der Auwera, \& D. Geeraerts (Eds.), Perspectives on Variation: Sociolinguistic, Historical, Comparative (pp. 7-42). Berlin: Mouton de Gruyter. http://dx.doi.org/10.1515/9783110909579.7

Babel, M. (2010). Dialect divergence and convergence in New Zealand English. Language in Society, 39, 437-456. 
Bell, A. (1984). Language style as audience design. Language in Society, 13 (2), $145-204$

Bellman, G. (1998). Between base dialect and standard language. Folia Linguistica, 32, 23-34.

Berruto, G. (1987). Sociolinguistica dell'italiano contemporaneo. Roma: La Nuova Italia Scientifica.

Celata, C., Meluzzi, C., \& Ricci, I. (2016). The sociophonetics of rhotic variation in Sicilian dialects and Sicilian Italian: Corpus, methodology and first results. Loquens, 3 (1), 025. doi: http://dx.doi.org/10.3989/loquens.2016.025

Celata, C., Vietti, A., \& Spreafico L. (2019) An articulatory account of rhotic variation in Tuscan Italian. In Gibson, M., \& Gil, J. (Eds.), Romance Phonetics and Phonology (pp. 91-117). Oxford: Oxford University Press.

Cerruti, M., \& Regis, R. (2005). 'Code switching' e teoria linguistica: La situazione italo-romanza. Rivista di linguistica, 17 (1), 179-208.

Coseriu, E. (1980). 'Historische Sprache' und 'Dialekt'. In J. Göschel, P. Ivić, \& K. Kehr (Eds.), Dialekt und Dialektologie: Ergebnisse des internationalen Symposions 'Zur Theorie des Dialekts' (pp. 106-122). Wiesbaden: Steiner.

Coupland, N. (2001). Dialect stylization in radio talk. Language in Society, 30 (3), 345-375.

Crocco, C. (2017). Everyone has an accent: Standard Italian and regional pronunciation. In M. Cerruti, C. Crocco, \& S. Marzo (Eds). Towards a New Standard: Theoretical and Empirical Studies on the Restandardization of Italian (pp. 89-117). Berlin/New York: Mouton De Gruyter.

Cukor-Avila, P., \& Bailey, G. (2011). The interaction of transmission and diffusion in the spread of linguistic forms. University of Pennsylvania Working Papers in Linguistics, 17 (2), 41-49.

D’Agostino, M., \& Paternostro, G. (2013). Parlanti e società dall'Unità ai nostri giorni in Sicilia. In Ruffino, G. (Ed.), Lingua e cultura in Sicilia (pp. 1-81). Palermo: Centro Studi Filologici e Linguistici Siciliani.

Dal Negro, S., \& Vietti, A. (2011). Italian and Italo-Romance dialects. International Journal of the Sociology of Language, 210, 71-92.

Ferguson, C. A. (1959). Diglossia. Word, 15 (2), 325-340.

Foulkes, P., Scobbie, J., \& Watt, D. (2010). Sociophonetics. In Hardcastle, W. J., Laver, J., \& Gibbon, F. E: (Eds.), The Handbook of Phonetic Sciences: Second Edition (pp. 703-754). London: Wiley-Blackwell.

Giles, H., Coupland, N., \& Coupland, I. (1991). Accommodation theory: Communication, context, and consequence. In H. Giles, J. Coupland, \& N. Coupland (Eds.). Studies in Emotion and Social Interaction: Contexts of Accommodation: Developments in Applied Sociolinguistics (pp. 1-68). Cambridge: Cambridge University Press.

Kristiansen, T., \& Coupland, N. (Eds.) (2011). Standard Languages and Language Standards in a Changing Europe. Oslo: Novus Press.

Labov, W. (1966). The Social Stratification of English in New York City. Philadelphia: University of Pennsylvania Press.

Labov, W. (1972). Sociolinguistic Patterns. Philadelphia: University of Pennsylvania Press.

Labov, W. (2001). Principles of Language Change: Social Factors (Vol. II). Oxford: Blackwell. 
Marotta, G. (2014). New parameters for the sociophnetic indexes. In C. Celata, \& S. Calamai (Eds), Advances in Sociophonetics (pp. 137-168). Amsterdam: John Benjamins.

Meluzzi, C. (2020). Sociofonetica di una varietà di koinè: Le affricate dentali nell'italiano di Bolzano. Pavia/Milano: Franco Angeli.

Mendoza-Denton, N. (2008). Homegirls: Language and Cultural Practice among Latina Youth Gangs. Oxford: Wiley-Blackwell. doi: http://dx.doi. org/10.1002/9780470693728

Morris, J. (2017). Sociophonetic variation in a long-term language contact situation: /1/-darkening in Welsh-English bilingual speech. Journal of Sociolinguistics, 21 (2), 183-207.

Nodari R., Celata C., \& Nagy N. (2019). Socio-indexical phonetic features in the heritage language context: Voiceless stop aspiration in the Calabrian community in Toronto. Journal of Phonetics, 73, 91-112.

Nycz, J. (2015). Second dialect acquisition: A sociophonetic perspective. Language and Linguistics Compass, 9 (11), 469-482.

Piccillo, G. (1969). Di alcune isoglosse più caratteristiche dei dialetti della Sicilia centrale. Bollettino del Centro di Studi Filologici e Linguistici Siciliani, 10, 287-296.

Piccitto, G. (1959). Il siciliano dialetto italiano. Orbis, 8, 181-197.

Pickering, M. J., \& Garrod, S. (2004). Toward a mechanistic psychology of dialogue. Behavioral and Brain Sciences, 27 (2),169-190.

Podesva, R., Jamsu Reynolds, J., Callier, P., \& Baptiste, J. (2015). Constraints on the social meaning of released / $\mathrm{t} / \mathrm{:}$ A production and perception study of US politicians. Language Variation and Change, 27, 59-87.

Rohlfs, G. (1966). Grammatica storica della lingua italiana e dei suoi dialetti: Fonetica (Vol. 1). Torino: Einaudi.

Ruffino, G. (2001). Sicilia. Roma: Laterza.

Scaglione, F. (2016). Il dialetto su Facebook: Identità, riflessioni (meta)linguistiche e nuovi usi sulle pagine campanilistiche palermitane. In G. Marcato (Ed.), Il dialetto nel tempo e nella storia (pp. 523-545). Torino: Cleup.

Schilling-Estes, N. (2002). Investigating Stylistic Variation. In J. K. Chambers, P. Trudgill, \& N. Schilling-Estes (Eds.), The Handbook of Language Variation and Change (pp. 375-401). London: Wiley-Blackwell.

Scobbie, J. (2006). (R) as a variable. In Brown, K. (Ed.), Encyclopedia of Language o Linguistics (2nd ed.) (pp. 337-344). Oxford: Elsevier.

Sharma, D. (2018). Style dominance: Attention, audience, and the 'real me'. Language in Society, 47(1), 1-31.

Van de Velde, H. \& van Hout, R. (2001). Patterns of /r/ variation. In R. van Hout, \& H. Van de Velde (Eds.). 'r-atics: Sociolinguistic, Phonetic and Phonological Characteristics of $/ r /$ (pp. 4-9). Bruxelles: ILVP.

Varvaro, A. (1988). Aree Linguistiche IV. Sicilia. In Holtus G., Metzeltin M., \& Schmitt C. (Eds.), Lexicon der Romanistischen Linguistik (pp. 716-731). Tübingen: Niemeyer. 
